Journal Club

Editor's Note: These short, critical reviews of recent papers in the Journal, written exclusively by graduate students or postdoctoral fellows, are intended to summarize the important findings of the paper and provide additional insight and commentary. For more information on the format and purpose of the Journal Club, please see http://www.jneurosci.org/misc/ifa_features.shtml.

\title{
A Cellular Mechanism for Main and Accessory Olfactory Integration at the Medial Amygdala
}

\author{
E. Mae Guthman ${ }^{1 \star}$ and $\odot$ Jorge Vera ${ }^{2 \star}$ \\ ${ }^{1}$ Neuroscience Graduate Program, University of Colorado Anschutz Medical Campus, Aurora, Colorado 80045, and ${ }^{2}$ Departamento de Biología, Universidad \\ de Chile, Santiago, Chile, 7800003 \\ Review of Keshavarzi et al.
}

Many vertebrates rely on their accessory and main olfactory systems (AOS and MOS, respectively) to interact with their environment. Shaped by evolution to drive the perception of volatile and nonvolatile molecules (for review, see Suárez et al., 2012), these sensory systems allow animals to react and learn about the distinct sets of chemical stimuli they encounter. The AOS detects molecules with evolutionarily stable and predictable meaning, such as the molecules emitted by predators and conspecifics-collectively known as semiochemicals. The AOS promotes innate behavioral responses when these cues are detected (Wilson and Stevenson, 2006). Conversely, the MOS detects chemical cues that have no innate meaning and helps to assign meaning to them through associative learning processes (Wilson and Stevenson, 2006).

Besides these functional differences, the AOS and MOS differ in how molecules reach the sensory epithelium, how the sensory information is processed, and where the processed information is sent

\footnotetext{
Received Nov. 30, 2015; revised Jan. 9, 2016; accepted Jan. 11, 2016.

We thank Ashley Bourke, Christian Cea-Del Rio, Jaclyn Essig, Molly Huntsman, Diego Restrepo, Jorge Mpodozis, Magdalena Sanhueza, and Rodrigo Suarez for critical review of the manuscript, and Maritza Oñate for assistance in figure construction.

The authors declare no competing financial interests.

*E.M.G. and J.V. contributed equally to this work.

Correspondence should be addressed to Jorge Vera, Departamento de

Biología, Universidad de Chile, Las Palmeras \#3425, Santiago, Chile, 7800003.E-mail: jorgeverab@gmail.com.

DOI:10.1523/JNEUROSCI.4304-15.2016

Copyright $\odot 2016$ the authors $\quad 0270-6474 / 16 / 362083-03 \$ 15.00 / 0$
}

(Suárez et al., 2012). Chemical cues reach the AOS at a specialized sensory epithelium located in the vomeronasal organ (VNO), a close-ended tubular structure connected to the nostrils and positioned at the base of the medial septum. The $\mathrm{VNO}$ is sequestered from airflow; thus, the chemical cues must solubilize with nasal fluids before entering the VNO via an active pumping mechanism (Meredith and O'Connell, 1979). Sensory neurons located in the VNO epithelium transduce the chemical cues and project to the accessory olfactory bulb (AOB), the first processing station of the AOS. The time course of activation of AOS neurons under naturalistic conditions is characterized by a slow increase in firing frequency (in the range of seconds) and a sustained response, without adaptation (Luo et al., 2003). In contrast, odorant molecules reach the MOS at the olfactory mucosa via airflow produced by an animal's sniffing behavior. Olfactory receptor neurons located in the main olfactory epithelium (MOE) transduce the odorants and transmit their signal to the main olfactory bulb (MOB), evoking a fast response on the millisecond timescale (Shusterman et al., 2011).

A major target of $\mathrm{AOB}$ output neurons is the medial amygdala (Suárez et al., 2012). Within the medial amygdala, neurons in the posteroventral division (MePV) respond to semiochemicals from predators (Bergan et al., 2014; Pérez-Gómez et al., 2015). MePV neurons project to the ventromedial hypo- thalamus (Keshavarzi et al., 2014), and predator odors activate neurons in both regions (Pérez-Gómez et al., 2015). Ventromedial hypothalamic neuronal activity is both necessary (Kunwar et al., 2015) and sufficient (Kunwar et al., 2015; PérezGómez et al., 2015) to drive defensive behaviors. Thus, the MePV processes chemical cues detected by the AOS and transmits the processed signal to the hypothalamic nuclei to initiate the output associated with innate behavioral responses.

Unlike $\mathrm{AOB}$ output neurons, $\mathrm{MOB}$ output neurons do not directly project to the medial amygdala; instead, they project to a variety of higher-order processing centers in the olfactory cortices (for review, see Bekkers and Suzuki, 2013). One of their targets is the cortical amygdala (CoA), which in turn sends projections to the medial amygdala (McDonald, 1998, their Table 3). These latter projections provide a means by which information from the MOS can influence AOS processing in the medial amygdala. In fact, although traditionally viewed as functionally independent systems, recent evidence suggests that the MOS contributes to the ability of the AOS to generate innate responses to biologically relevant molecules (Martínez-García et al., 2009). How these systems interact at the cellular level was unknown until recently, however.

In a recent study published in The Journal of Neuroscience, Keshavarzi et al. (2015) provided novel evidence that AOS and MOS inputs converge on individual 


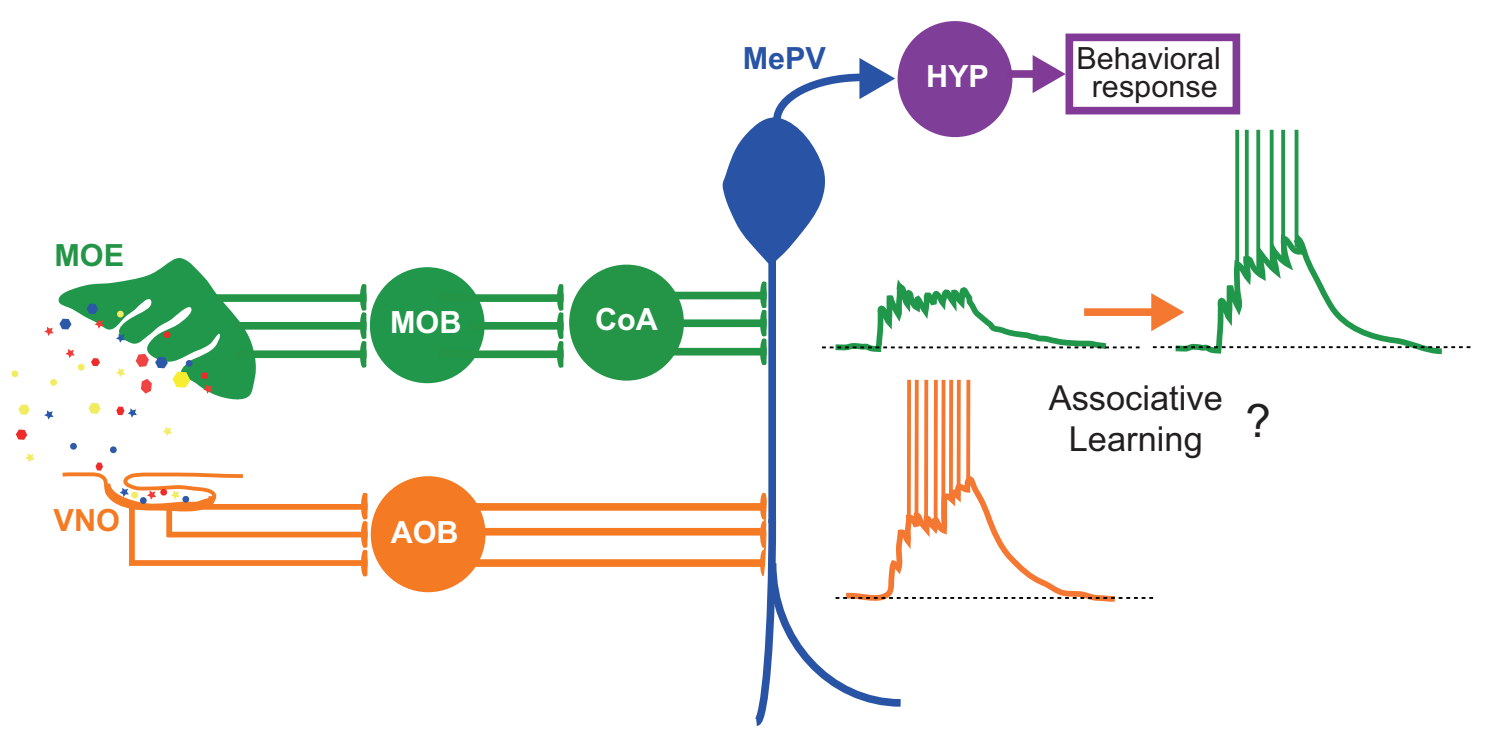

Figure 1. Proposed cellular mechanism for associative learning between accessory and main olfactory pathways. MOS (green) input synapses at the proximal dendrites of MePV neurons and AOS (orange) synapses at distal dendritic sites. Small colored shapes on the left represent a variety of molecules. Voltage traces to the right represent the effect of associative learning on MePV neuronal responses to MOS and AOS input.

medial amygdala neurons. The authors used acute coronal brain slices from GAD67-GFP transgenic mice, which allowed detection of non-GABAergic (nonGFP expressing) projection neurons in the MePV, as well as selective and reliable electrical stimulation of $\mathrm{CoA}$ and $\mathrm{AOB}$ inputs (via direct electrical stimulation of deep CoA layers lateral to the MePV and the superficial molecular layer of MePV, respectively). Using standard electrophysiological techniques, Keshavarzi et al. (2015) demonstrated that individual MePV neurons receive excitatory input from both AOS and MOS, thereby serving as convergent hubs for both pathways. Importantly, the authors showed that the excitatory input from both systems was mediated by AMPA and NMDA receptors (AMPAR and NMDAR, respectively; Keshavarzi et al., 2015, their Fig. 2A). In addition, the authors used a battery of techniques, including current-source density analysis of evoked synaptic potentials, selective blockade of distal synapses, and calcium imaging paired with wholecell recordings, to reveal that the inputs from the two olfactory systems are spatially segregated on amygdalar neurons. Specifically, they demonstrate that $\mathrm{AOB}$ inputs produced synaptic depolarization at distal dendritic sites of MePV neurons, whereas CoA inputs produced synaptic depolarization at proximal dendritic sites (Keshavarzi et al., 2015, their Figs. 3-5).

To investigate possible functional differences between the synaptic inputs, the authors activated presynaptic fibers of each pathway with a $50 \mathrm{~Hz}$ stimulus train and recorded evoked responses under whole-cell current-clamp. MePV neurons responded to stimulation of $\mathrm{AOB}$ input with increasing depolarization up to threshold, at which point they fired a train of action potentials. In contrast, the neurons responded to identical stimulation of CoA input with subthreshold voltage responses (Keshavarzi et al., 2015, their Fig. $6 A)$. The differential functional impact of $\mathrm{AOB}$ and $\mathrm{CoA}$ inputs emerges as a remarkable characteristic of the MeA neuronal circuits, displaying synaptic and electrical properties that strongly favor the distal $\mathrm{AOB}$ inputs.

Neurons use different mechanisms to compensate for dendritic filtering of distal synaptic inputs (for review, see Magee, 2000). For example, in hippocampal and cortical pyramidal neurons, active conductances enhance dendritic propagation of distant inputs (Migliore and Shepherd, 2002). Additionally, in these same neurons, synaptic current amplitude increases proportionally with distance from the soma such that the somatic impact of proximal and distal inputs is equivalent (Magee, 2000). One mechanism for this increase in current amplitude at distal synapses is an increase in AMPAR number (Smith et al., 2003) and another is an increase in the ratio of the amplitudes of NMDAR- to AMPAR-mediated currents (Otmakhova et al., 2002). Since NMDARs have slower kinetics than AMPARs, a relative increase in NMDAR-mediated current produces individual EPSPs with slower time courses that are more easily integrated over time, thereby producing a greater somatic depolarization (Magee, 2000).

Interestingly, Keshavarzi et al. (2015) found that nearly $50 \%$ of the AOB-driven somatic depolarization of MePV neurons depended on NMDARs, whereas CoAdriven somatic depolarization showed no dependence on NMDARs despite the fact that synapses associated with CoA input showed NMDAR-mediated currents (Keshavarzi et al., 2015, their Figs. 2A, $6 B-D)$. In fact, this finding is consistent with the increase in the amplitude of NMDAR-mediated currents at distal synapses that occurs in hippocampal neurons as a mechanism to increase their somatic impact (Magee, 2000).

It seems plausible that the anatomical and functional segregation of inputs onto MePV neurons operates as a cellular mechanism for associative learning between the AOS and MOS. According to the available data, it can be speculated that under simultaneous activation of both pathways, $\mathrm{AOB}$ inputs will depolarize $\mathrm{MePV}$ neurons to threshold, promoting correlated firing between the MePV neurons and CoA input. This correlated activity between the MePV neurons and CoA input would promote NMDAR-dependent long-term synaptic potentiation, or LTP (i.e., an increase in synaptic strength after coactivation of presynaptic and postsynaptic neurons; Barrionuevo and Brown, 1983). Thus, the stronger $\mathrm{AOB}$ inputs would act as the "teaching" signal for the weaker CoA inputs in a manner similar to the well studied LTP in the hippocampus and basolateral amygdala (Bliss and Collingridge, 1993; Le- 
Doux, 2000). Following LTP induction, the MOS signal transmitted by CoA inputs would be sufficient to activate MePV neurons and their downstream targets (for a schematic of this process, see Fig. 1). Whether LTP occurs between AOS and MOS inputs in individual MePV neurons under physiological conditions requires further investigation. Simple experiments to test this hypothesis can be conducted using the same preparation as Keshavarzi et al. (2015) and well described LTP protocols (Barrionuevo and Brown, 1983).

Such LTP between CoA and AOB inputs might underlie the associative learning that occurs when animals encounter specific patterns of odorant molecules that correlate with the presence of a predator or conspecific (Martínez-García et al., 2009). Importantly, the associative learning likely provides adaptive value to the animals by broadening the set of stimuli that activate the neural pathways for the innate behavioral responses to the predator or conspecific (Martínez-García et al., 2009). Before the recent report by Keshavarzi and colleagues (2015), the cellular mechanisms that underlie associative learning between the olfactory systems were unknown. Their results clearly demonstrate that individual $\mathrm{MePV}$ neurons receive input from both the AOS and MOS and suggest that the stronger AOS input could act to promote LTP at the synapses of the weaker MOS inputs. Their findings suggest that a more complete understanding of the cellular mechanisms that underlie learned, adaptive behaviors can be attained in the near future.

\section{References}

Barrionuevo G, Brown TH (1983) Associative long-term potentiation in hippocampal slices. Proc Natl Acad Sci U S A 80:7347-7351. CrossRef Medline

Bekkers JM, Suzuki N (2013) Neurons and circuits for odor processing in the piriform cortex. Trends Neurosci 36:429-438. CrossRef Medline

Bergan JF, Ben-Shaul Y, Dulac C (2014) Sexspecific processing of social cues in the medial amygdala. Elife 3:e02743. CrossRef Medline

Bliss TV, Collingridge GL (1993) A synaptic model of memory: long-term potentiation in the hippocampus. Nature 361:31-39. CrossRef Medline

Keshavarzi S, Sullivan RK, Ianno DJ, Sah P (2014) Functional properties and projections of neurons in the medial amygdala. J Neurosci 34:8699-8715. CrossRef Medline

Keshavarzi S, Power JM, Albers EH, Sullivan RK, Sah P (2015) Dendritic organization of olfactory inputs to medial amygdala neurons. J Neurosci 35: 13020-13028. CrossRef Medline

Kunwar PS, Zelikowsky M, Remedios R, Cai H, Yilmaz M, Meister M, Anderson DJ (2015) Ventromedial hypothalamic neurons control a defensive emotion state. Elife 4:1-30. CrossRef Medline

LeDoux JE (2000) Emotion circuits in the brain. Annu Rev Neurosci 23:155-184. CrossRef Medline

Luo M, Fee MS, Katz LC (2003) Encoding pheromonal signals in the accessory olfactory bulb of behaving mice. Science 299:1196-1201. CrossRef Medline

Magee JC (2000) Dendritic integration of excitatory synaptic input. Nat Rev Neurosci 1: 181-190. CrossRef Medline

Martínez-García F, Martínez-Ricós J, AgustínPavón C, Martínez-Hernández J, Novejarque A, Lanuza E (2009) Refining the dual olfactory hypothesis: pheromone reward and odour experience. Behav Brain Res 200:277286. CrossRef Medline

McDonald AJ (1998) Cortical pathways to the mammalian amygdala. Prog Neurobiol 55: 257-332. CrossRef Medline

Meredith M, O'Connell RJ (1979) Efferent control of stimulus access to the hamster vomeronasal organ. J Physiol 286:301-316. CrossRef Medline

Migliore M, Shepherd GM (2002) Emerging rules for the distributions of active dendritic conductances. Nat Rev Neurosci 3:362-370. CrossRef Medline

Otmakhova NA, Otmakhov N, Lisman JE (2002) Pathway-specific properties of AMPA and NMDA-mediated transmission in CA1 hippocampal pyramidal cells. J Neurosci 22: 1199-1207. Medline

Pérez-Gómez A, Bleymehl K, Stein B, Pyrski M, Birnbaumer L, Munger SD, Leinders-Zufall T, Zufall F, Chamero P (2015) Innate predator odor aversion driven by parallel olfactory subsystems that converge in the ventromedial hypothalamus. Curr Biol 25: 1340-1346. CrossRef Medline

Shusterman R, Smear MC, Koulakov AA, Rinberg D (2011) Precise olfactory responses tile the sniff cycle. Nat Neurosci 14:1039-1044. CrossRef Medline

Smith M, Ellis-Davies and Magee J (2003) Mechanism of the distance-dependent scaling of Schaffer colateral synapses in rat CA1 pyramidal neurons. J Physiol 548:245-258. Medline

Suárez R, García-González D, de Castro F (2012) Mutual influences between the main olfactory and vomeronasal systems in development and evolution. Front Neuroanat 6:50. CrossRef Medline

Wilson DA, Stevenson RJ (2006) Learning to smell: olfactory perception from neurobiology to behavior, 1st ed. Baltimore: Johns Hopkins UP. 